\title{
Reflexões sobre a Aprendizagem Colaborativa / Coaprendizagem como Método para a Educação Continuada
}

Reflections on Collaborative Learning / Co-Learning as a method for Continuing Education

Kátia Denise Moreiraํㅜ, Elaine Thais da Silva Lima², Marcos Baptista Lopez Dalmau e Alexandre Marino Costa ${ }^{4}$ 1,2,3,4 Universidade Federal de Santa Catarina, UFSC 


\title{
Resumo
}

As reflexões sobre a aprendizagem são desenvolvidas a partir de vertentes variadas, visto a característica transdisciplinar do fenômeno e, também, o alinhamento epistemológico seguido ao se tratar do tema. Nessa direção, considerado um posicionamento mais construtivista, este estudo tem como objetivo refletir sobre a aprendizagem colaborativa / coaprendizagem como estratégia para a educação continuada. Em termos metodológicos, trata-se de uma pesquisa bibliográfica, cuja proposta não contempla a verificação empírica, porém permite a construção de um arcabouço teórico para o aprofundamento da questão, quando na sua aplicação. Ao final da reflexão, considera-se que a aprendizagem colaborativa/ coaprendizagem se alinha aos propósitos da educação continuada e, sendo assim, é, teoricamente, considerada uma estratégia válida.

Palavras-chave: aprendizagem, aprendizagem colaborativa, coaprendizagem, educação continuada

\begin{abstract}
The reflections on learning are developed on various aspects, given the transdisciplinary characteristic of the phenomenon and also the epistemological alignment followed when dealing the theme. In this direction, considered a constructivist position, this study aims to reflect on collaborative learning / co-learning as a strategy for continuing education. In methodological terms, this is a bibliographic research, in which the proposal does not include empirical verification, but allows a theoretical construction to deepen the issue, when applied. At the end of the reflection, it is considered that collaborative learning / co-learning aligns with the purposes of continuing education and therefore is, in theory, considered a valid strategy.
\end{abstract}

Keywords: learning, collaborative learning, co-learning, continuing education 
A aprendizagem tem significância multiforme, que perpassa vários contextos, associando-se a variadas concepções, todavia, a obtenção do conhecimento é um fenômeno comum entre aqueles que teorizam sobre o termo (Piaget, 1980; Ausubel, 1983; Vygotsky, 1989; Perrenoud, 1999). É consenso entre esses teóricos, a linha de pensamento sobre a aprendizagem tratar de um processo construtivo, ou seja, que não acontece de forma imediata, mas resulta da interação e vivência do sujeito com aquilo que se pretende aprender.

Associado a isso, observa-se, em tempos contemporâneos, que a sociedade exige cada vez mais dos atores sociais que a compõe, seja no que diz respeito ao contexto econômico, político e social, ou nos aspectos das relações humanas que envolvem os relacionamentos interpessoais e profissionais. Nesse sentido, destacam-se como meios para a inserção social desses sujeitos a busca pelo autodesenvolvimento e a aprendizagem contínua (Eboli, 2001).

Tal evidência conecta-se ao fato de instituições comprometerem-se cada vez mais com a educação, por meio do desenvolvimento dos indivíduos, a partir de "sistemas educacionais que privilegiem o desenvolvimento de atitudes, posturas e habilidades, em vez de privilegiar, apenas, o conhecimento técnico e instrumental" (Eboli, 2001, p. 111). Ou seja, a aposta é no desenvolvimento de competências, que na prática insere o sujeito em "[...] situações complexas envolvendo problemas que exigem a mobilização e a busca de saberes para a sua resolução" (Küller \& Rodrigo, 2013, p. 65).

Assim, ao se pensar sobre o processo de aprendizagem, tem-se como desafio fazer com que o sujeito se qualifique, promovendo a ele a possibilidade de "[...] navegar na complexidade" (Le Boterf, 2003, p. 39), por meio do: a) saber agir com pertinência; b) saber mobilizar saberes e conhecimentos em um contexto profissional; c) saber integrar ou combinar saberes múltiplos e heterogêneos; d) saber transpor; e) saber aprender e aprender a aprender; e f) saber envolver-se (Le Boterf, 1999, 2003).

E, ao se tratar de complexidade da aprendizagem, associada aos pontos ora expressos, corrobora-se à perspectiva de Delors (2004) de que a acumulação de conhecimento no começo da vida não significa sabedoria para a vida toda. Segundo o autor, há de se explorar esse processo ao longo de toda a vida (educação continuada), enriquecer aquilo internalizado em um primeiro momento e, ainda, adaptar para um mundo de mudanças. Sob essa perspectiva, Delors (2004) apresenta os quatro pilares da educação ao longo da vida, quais sejam: a) aprender a conhecer, b) aprender a fazer, c) aprender a viver juntos e como o outro e d) aprender a ser.

Assim, compreendida uma conjuntura na qual o sujeito vive em sociedade, acredita-se que a aprendizagem colaborativa/coaprendizagem está associada aos quatro pilares propostos por Delors (2004), fundamentada pela concepção de trabalhar em grupo (Leite, Passos, Torres, \& Alcantara, 2005). É importante dizer também, que esse tipo de abordagem da aprendizagem respeita e destaca as habilidades e contribuições individuais, que se conectam, na forma de cooperação, entre os membros de um grupo (Panitz, 1999). Dessa maneira, considerado o pressuposto de associação entre os fenômenos tem-se como questionamento para desenvolvimento deste estudo: como se configura o alinhamento entre a aprendizagem colaborativa/coaprendizagem e educação continuada? 
A partir do indagamento problema, este estudo tem como objetivo refletir sobre a aprendizagem colaborativa/coaprendizagem como estratégia para a educação continuada. Justifica-se a escolha da matéria pela relevância em se tratar da aprendizagem não apenas como um fenômeno que acontece em um momento único da vida do sujeito, mas sim durante toda sua vida, visto que se vive em uma sociedade dinâmica e multifacetada. Por se tratar de um ensaio teórico a estrutura deste estudo não tem por finalidade a verificação dos elementos teórico-conceituais tratados. Todavia, não se presume o rompimento com a dicotomia sujeito/objeto, que permeia a realidade dos fenômenos estudados empiricamente (Wheten, 1989); inclusive, as reflexões ora expostas buscam aprofundar questões que poderão ser tratadas futuramente in loco.

\section{A Educação Continuada}

Antes de tratar da aprendizagem foco deste estudo, acredita-se ser importante apresentar as concepções teóricas sobre o fenômeno, que ancoram a linha de reflexão. Nessa direção, retoma-se a ideia de que a aprendizagem é interdisciplinar, fato que lhe confere amplitude em termos de inserção nos campos do conhecimento.

Assim, considerada essa característica, tem-se com base em Ausubel (1983), Salvador (1994) e Ferreira (1999), uma concepção estruturada de aprendizagem sob os seguintes aspectos: a) ação de reter algo, de fixar algo na memória, qualquer ofício, arte, ciência ou uma profissão; b) processo de obter conhecimento por meio de escolarização; c) aprender algo ou alguma coisa do estudo; d) adquirir habilidade prática; e) conhecimento ou habilidade obtido por meio de treino e/ou estudo; f) reter algo na memória, esforço deliberado para se obter conhecimento sobre algo; e g) vivência, carga afetiva e de sensibilidade.

Ou seja, a base da concepção se fundamenta no processo de obtenção do conhecimento e, desse modo, pode-se dizer que se trata de uma ação construtiva, que não ocorre de forma imediata, mas sim por meio da interação e vivência do sujeito com aquilo que se pretende aprender. Disposto tal posicionamento, apresenta-se na Figura 1, algumas das principais concepções acerca da aprendizagem:

Figura 1

Concepções sobre a Aprendizagem

Teórico

Jean Piaget (1896-1980)
Concepções da Aprendizagem

O sujeito constrói esquemas de assimilação mental, no sentido de tratar a realidade e essa, por sua vez, supõe um esquema de assimilação. O autor destaca que, quando a mente assimila, ela incorpora a realidade e age, impondo-se ao meio. Quando a ação não assimila uma situação, a mente se modifica e ocorre a acomodação, a qual leva a modificação do esquema de assimilação ou a construção de novos, promovendo assim o desenvolvimento cognitivo.

Vygotsky (1989)
A interação do homem com outros sujeitos promove a construção do pensar (conhecimento). 0 trabalho humano, que une a natureza ao homem, cria a cultura e a história do ser humano, desenvolve a atividade coletiva, as relações sociais e a utilização de instrumentos, os quais são utilizados pelo trabalhador, ampliando as possibilidades de transformar a natureza, sendo assim, um objeto social. 


\begin{tabular}{|c|c|}
\hline Teórico & Concepções da Aprendizagem \\
\hline Ausubel (1997) & $\begin{array}{l}\text { [...] o aprendizado do sujeito depende de uma estrutura cognitiva prévia, que se relaciona com } \\
\text { uma nova informação que deve ser entendida como 'estrutura cognitiva', que significa, } \\
\text { o conjunto de conceitos, ideias que um sujeito tem em um determinado campo do } \\
\text { conhecimento ou sobre sua organização. }\end{array}$ \\
\hline Perrenoud (1999) & $\begin{array}{l}\text { Introduz os ciclos de aprendizagem. Alerta para a necessidade, não só de mudança da estrutura } \\
\text { curricular, mas das práticas profissionais, dos valores, das atitudes, das representações, dos } \\
\text { conteúdos, das competências, da identidade e dos projetos de cada um. O autor ressalta que } \\
\text { é aquilo que os tecnocratas chamam de "fator humano" que passa pela formação. }\end{array}$ \\
\hline Delors (2004) & $\begin{array}{l}\text { Apresenta o conceito de educação ao longo da vida. A educação ao longo de toda a vida [...] deve } \\
\text { fazer com que cada indivíduo saiba conduzir o seu destino, num mundo onde a rapidez das } \\
\text { mudanças se conjuga com o fenômeno da globalização para modificar a relação que homens } \\
\text { e mulheres mantem com o espaço e o tempo. As alterações que afetam a natureza do } \\
\text { emprego, ainda circunscritas a uma parte do mundo, vão, com certeza, generalizar-se e levar } \\
\text { a uma reorganização dos ritmos da vida. A educação ao longo de toda a vida torna-se assim, } \\
\text { para nós, o meio de chegar a um equilíbrio mais perfeito entre trabalho e aprendizagem bem } \\
\text { como ao exercício de uma cidadania ativa. }\end{array}$ \\
\hline
\end{tabular}

Nota: Piaget (1964), Vygotsky (1989), Perrenoud (1999), Delors (2004)

A partir das concepções expostas, é possível compreender que o convívio social promove a aprendizagem e, nesse sentido, respalda este estudo nas discussões sobre a significância da aprendizagem, como resultante de um processo de interação entre uma estrutura de conhecimento pré-existente, que ao se relacionar com uma nova informação provoca mudanças na dimensão anterior.

A esse pressuposto insere a educação continuada, a qual encontra raízes na interpretação de que o sujeito tem necessidades de conhecimento, que se prolongam ao longo da vida (Arouca, 1996). Nessa direção, Delors (2004, p. 89) argumenta "à educação cabe fornecer, de algum modo, os mapas de um mundo complexo e constantemente agitado e, ao mesmo tempo, a bússola que permite navegar através dele".

Sobre os objetivos da educação continuada, Santos (1999) defende como finalidade evitar que o profissional, frente à dinamicidade dos dias atuais, se desatualize em termos de conhecimentos técnicos, práticos e culturais e, consequentemente, perca a capacidade de exercer suas funções com a competência necessária. Sob essa perspectiva, esse tipo de educação prepara o sujeito para o alcance da efetividade naquilo que já realiza (Prosdócimo \& Ohira 2000) e, ainda, segundo os autores, focaliza no como fazer e na capacitação para atuar tanto no presente, quanto no futuro.

Dessa maneira, tem-se a educação continuada focada na concepção de que, para o sujeito, não basta apenas estocar conhecimento em uma determinada etapa da vida “É, antes, necessário estar à altura de aproveitar e explorar, do começo ao fim da vida, todas as ocasiões de atualizar, aprofundar e enriquecer estes primeiros conhecimentos, e de se adaptar a um mundo em mudança” (Delors, 2004, p. 89). Assim, a continuidade da 
educação desponta como fator determinante para constante atualização e qualificação e, de acordo com os pressupostos de Jaques Delors (2004), pode ser desenvolvida a partir de quatro pilares, descritos na Figura 2: Figura 2

Caracterização dos Quatro Pilares da Educação

\begin{tabular}{|c|c|c|}
\hline Pilar & Concepção & Caracterização (Síntese) \\
\hline Aprender a Conhecer & $\begin{array}{l}\text { Supõe-se, antes de tudo, } \\
\text { aprender a aprender, } \\
\text { exercitando a } \\
\text { atenção, a memória } \\
\text { e o pensamento. } \\
\text { O processo da } \\
\text { aprendizagem do } \\
\text { conhecimento } \\
\text { nunca acaba e pode } \\
\text { enriquecer-se com } \\
\text { qualquer experiência. }\end{array}$ & $\begin{array}{l}\text { - Domínio dos próprios instrumentos do conhecimento; } \\
\text { - } \quad \text { Prazer de compreender, de conhecer, de descobrir; } \\
\text { sentido crítico e permite compreender o real, mediante a } \\
\text { aquisição de autonomia na capacidade de discernir; } \\
\text { - O conhecimento é múltiplo e evolui infinitamente, assim, torna- } \\
\text { se cada vez mais inútil tentar conhecer tudo em apenas um } \\
\text { momento da vida; } \\
\text { É preciso combinar, tanto no ensino como na pesquisa, dois } \\
\text { métodos apresentados, muitas vezes, como antagônicos: o } \\
\text { método dedutivo por um lado e o dedutivo por outro; } \\
\text { A educação pode ser considerada bem-sucedida se conseguir } \\
\text { transmitir as pessoas o impulso e as bases que façam com que } \\
\text { continuem a aprender ao longo de toda a vida, no trabalho, } \\
\text { mas também fora dele. }\end{array}$ \\
\hline Aprender a Fazer & $\begin{array}{l}\text { Aprendizagem ligada à } \\
\text { questão da formação } \\
\text { profissional: como } \\
\text { ensinar o aluno a } \\
\text { colocar em prática os } \\
\text { seus conhecimentos } \\
\text { e como adaptar a } \\
\text { educação ao trabalho } \\
\text { futuro. }\end{array}$ & $\begin{array}{l}\text { - Aprender a fazer não pode ter o significado simples de preparar } \\
\text { alguém para uma tarefa material; } \\
\text { - As aprendizagens devem evoluir e não serem consideradas } \\
\text { como simples transmissão de práticas mais ou menos rotineiras, } \\
\text { embora estas continuem a ter um valor formativo que não é de } \\
\text { desprezar; } \\
\text { O progresso técnico modifica, inevitavelmente, as qualificações } \\
\text { exigidas pelos novos processos de produção e, sendo assim, as } \\
\text { tarefas físicas são substituídas pelas mais intelectuais, mentais; } \\
\text { ale lembrar que a aprendizagem não se destina, apenas, a um } \\
\text { só trabalho, mas tem como objetivo mais amplo preparar para } \\
\text { uma participação formal ou informal no desenvolvimento do } \\
\text { indivíduo. }\end{array}$ \\
\hline
\end{tabular}




\begin{tabular}{|c|c|c|}
\hline Pilar & Concepção & Caracterização (Síntese) \\
\hline $\begin{array}{l}\text { Aprender a viver } \\
\text { juntos, aprender } \\
\text { a viver com os } \\
\text { outros }\end{array}$ & $\begin{array}{l}\text { A educação tem como } \\
\text { missão, por um } \\
\text { lado, transmitir } \\
\text { conhecimentos sobre a } \\
\text { diversidade da espécie } \\
\text { humana e, por outro, } \\
\text { levar as pessoas a } \\
\text { tomar consciência } \\
\text { das semelhanças e } \\
\text { da interdependência } \\
\text { entre todos os seres } \\
\text { humanos. }\end{array}$ & 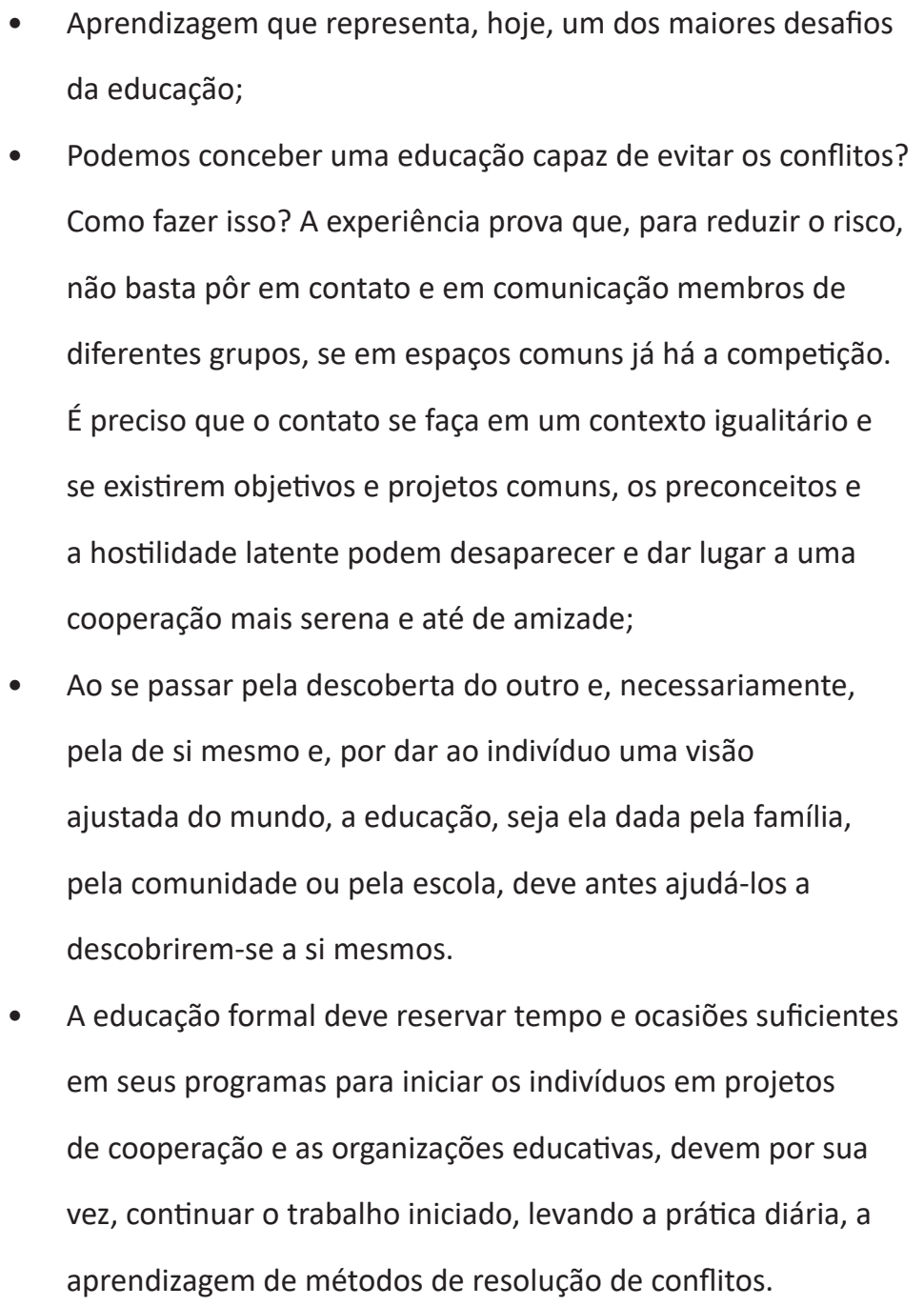 \\
\hline Aprender a ser & $\begin{array}{l}\text { A educação dever } \\
\text { contribuir para o } \\
\text { desenvolvimento total } \\
\text { da pessoa - espírito } \\
\text { e corpo, inteligência, } \\
\text { sensibilidade, } \\
\text { sentido estético, } \\
\text { responsabilidade } \\
\text { pessoal e } \\
\text { espiritualidade. }\end{array}$ & $\begin{array}{l}\text { - Todo ser humano deve ser preparado, especialmente graças à } \\
\text { educação que recebe na juventude, para elaborar pensamentos } \\
\text { autônomos e críticos e para formular os seus próprios juízos de } \\
\text { valor, de modo a poder decidir, por si mesmos, como agir nas } \\
\text { diferentes circunstâncias da vida; } \\
\text { A educação parece ter, como papel essencial, conferir a todos } \\
\text { os seres humanos a liberdade de pensamento, discernimento, } \\
\text { sentimentos e imaginação de que necessitam para desenvolver } \\
\text { os seus talentos e permanecerem, tanto quanto possível, donos } \\
\text { do seu próprio destino; } \\
\text { O desenvolvimento do ser humano, que se desenrola desde o } \\
\text { nascimento até à morte, é um processo dialético que começa } \\
\text { pelo conhecimento de si mesmo para se abrir, em seguida, à } \\
\text { relação com o outro. }\end{array}$ \\
\hline
\end{tabular}

Nota: Elaborado pelos autores com base em Delors (2004).

A partir da Figura 2, é possível identificar uma indissociabilidade entre os quatro pilares e, também, que não há distinção para uma ou outra fase da vida do sujeito, em que devam ser aplicados, justificando assim, o 
idealizado pela educação ao longo de toda a vida. Identifica-se que aprender a conhecer é oportunizar ao sujeito conhecimentos técnicos, sociais e culturais, que servem para embasar o fazer tanto no campo profissional, como social. Ainda, aprender a conhecer possibilita a compreensão do outro e o fazer propicia o desenvolvimento de trabalhos e projetos conjuntos. Essa dinâmica assegura ao sujeito o aprender a ser, uma vez que, o indivíduo evolui como um todo - intelectual, responsável, sensível e cooperativo.

\section{A Aprendizagem Colaborativa/Coaprendizagem}

Ao se tratar de um processo cooperativo adentra-se para o campo da aprendizagem colaborativa/ cooperativa, que tem como princípio o compartilhamento do conhecimento (Leite et al, 2005). Dito de outra forma, esse tipo de aprendizagem se processa por meio da interação e da troca entre os sujeitos, cujo objetivo é melhorar a competência dos indivíduos, por intermédio dos trabalhos cooperativos em grupo (Leite et al, 2005). Dillenbourg (1999) menciona que se trata de uma situação em que duas ou mais pessoas aprendem juntas, podendo ser um pequeno grupo, uma comunidade ou uma sociedade, que pretendem aprender algo, que pode ser interpretado como seguir um curso, estudar o material de um curso, realizar atividades de aprendizagem, como resolução de problemas ou aprender com a prática de trabalho ao longo da vida. A ideia de que 'juntos' pode ser interpretada como diferentes formas de interação: presencial ou não, síncrona ou não, frequente no tempo ou não. A questão é a de que o esforço para a aprendizagem é verdadeiramente conjunto.

Importante lembrar que a aprendizagem colaborativa tem sua concepção discutida, testada e implementada desde o século XVIII, ganhando destaque nos anos de 1990, quando professores do ensino superior adaptaram a aprendizagem cooperativa a prática de ensino (Leite et al., 2005). Todavia, apesar de esse tipo de aprendizagem ter se disseminado, com uma ampla variedade de maneiras de se materializar, em diferentes disciplinas e campos, não há um consenso sobre a definição correta da metodologia, no entanto, existem algumas características subjacentes que a modelam (Laal \& Laal, 2012).

Ressalta-se que a colaboração entre o sujeito ganha destaque nessa abordagem, sob a perspectiva da construção de consenso, por intermédio da cooperação entre os indivíduos, em contraposição à competição (Panitz, 1999). Na aprendizagem colaborativa/coaprendizagem os sujeitos são desafiados tanto social, quanto emocionalmente a ouvir diferentes perspectivas e são obrigados a articular e defender suas ideias, por meio do diálogo (Laal \& Laal, 2012). Vale destacar que a colaboração e a cooperação são termos complementares, todavia, apesar da similaridade entre as abordagens, existem autores que pontuam algumas diferenças entre elas, conforme exposto na Figura 3. 


\section{Figura 3}

Diferenças entre aprendizagem colaborativa e cooperativa

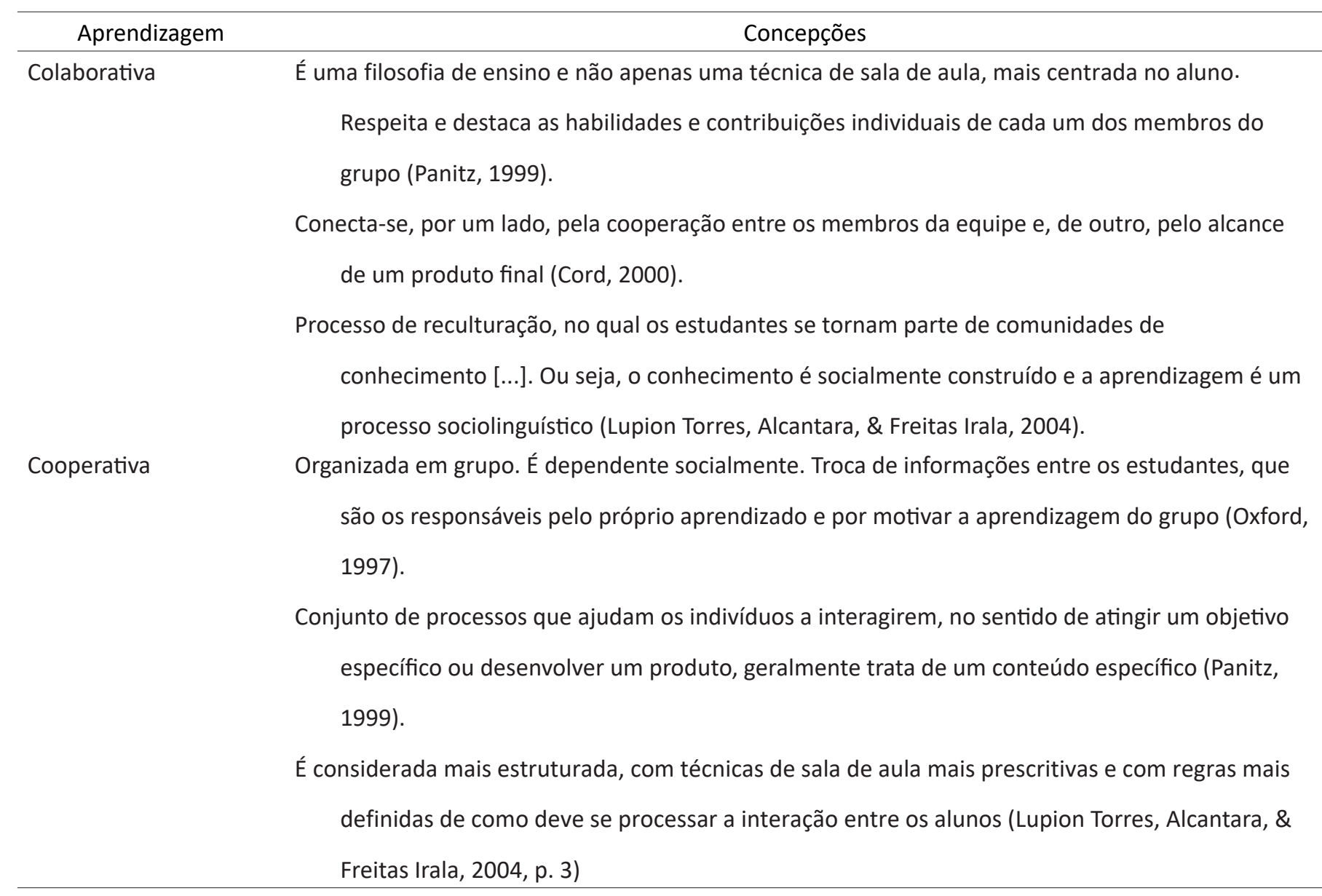

Nota: Elaborado pelos autores com base em Oxford (1997), Panitz (1999), Cord (2000) e Lupion Torres, Alcantara, Freitas Irala (2004).

Conforme já exposto, este estudo considera a complementaridade das duas abordagens e, assim sendo, justifica-se a denominação utilizada - aprendizagem colaborativa/cooperativa. Acerca desse tipo de aprendizagem, acentua-se a possibilidade de interação e da troca entre os estudantes, com vistas a melhora de sua atuação no trabalho (Leite et al, 2005). Observa-se que essa característica possibilita que

a aprendizagem ocorra por meio de um processo dinâmico e participativo, que tem como consequência, a construção coletiva do conhecimento (Okada, 2014).

Naquilo que se refere à forma de aplicação da aprendizagem colaborativa/coaprendizagem, tem-se que ela pode ocorrer em sala de aula, grupos focais, oficinas e, contemporaneamente, pela educação à distância. Observase que a aprendizagem oportunizada pelas redes digitais possibilitou a expansão do conhecimento e é uma das bases da educação do século XXI (Okada, 2014). Inclusive para a autora, as marcas - colaboração e abertura - são consideradas a essência do conceito de coaprender, fortalecendo a compreensão de complementaridade entre colaboração e cooperação. Nessa direção a coaprendizagem:

[...] compreende desde as diversas reinterpretações, reconstruções e redistribuições de informações, reflexões, teorias e práticas resultando em conhecimento; como também, domínio tecnológico, interação com visão ético-critica, novos questionamentos coletivos com coinvestigação colaborativa visando com 
isso, inovação em rede; possibilitando, portanto o desenvolvimento mais amplo de competências (Okada, 2014, p. 16).

É interessante acrescentar que para a prática da aprendizagem colaborativa/coaprendizagem existem competências-chave, inseridas em cinco domínios: constitutivo, interpessoal, cognitivo, instrumental e operacional e, variam entre flexibilidade, comunicação, comprometimento, responsabilidade, criatividade, criticidade, utilização de recursos tecnológicos, empatia, paciência, proatividade e iniciativa (Okada, 2014). Postas as argumentações teóricas, na sequência, busca-se o alinhamento entre os fenômenos.

\section{Procedimentos Metodológicos}

A partir do objetivo proposto neste estudo, refletir sobre a aprendizagem colaborativa/coaprendizagem como estratégia para a educação continuada, buscou-se uma combinação de procedimentos metodológicos, para fins de estabelecer os caminhos percorridos no estudo ora apresentado (Gerhardt \& Silveira, 2009).

Nesse sentido, em termos de natureza, trata-se de um estudo básico, que busca ampliar o conhecimento sobre determinado assunto (Saunders, Lewis \& Thornhill, 2009), neste caso, a discussão sobre uma determinada metodologia de aprendizagem, a colaborativa/coaprendizagem, como base para educação continuada. No que se refere aos objetivos, a pesquisa é descritiva, pois descreve a relação entre as variáveis escolhidas para reflexão (Vergara, 2010). Ou seja, o alinhamento proposto sobre um tipo de aprendizagem específico servir como base para determinada forma de educação.

Nesta reflexão não se intencionam quantificações, mas sim a construção de uma realidade específica (Triviños, 2010), portanto, se trata de um estudo qualitativo, no qual pretende-se a compreensão de um fenômeno - a aprendizagem colaborativa/coaprendizagem inserida no contexto da educação continuada, a partir da interpretação do pesquisador frente à relevância que ele considera em termos de complexidade da situação (Creswell, 2009).

Como estratégia, utilizou-se a bibliográfica, visto que o estudo é ancorado em um conjunto de conhecimentos sistematizados sobre o tema explorado, que se sustenta em materiais publicados, como, livros, artigos de revistas acadêmicas e de periódicos científicos (Saunders, Lewis \& Thornhill, 2009). Assim, fez-se uma pesquisa preliminar em bases como Web Of Science, Ebsco Host e Google Academic, além da busca em livros que abordassem a temática ora explorada. A escolha dos citados indexadores de dados sustentou-se por estarem associados aos estudos da área organizacional, tanto no contexto nacional, como no internacional. Observa-se que para a busca não se definiu um recorte temporal específico, uma vez que o foco era conhecer os trabalhos e sua contribuição. Encontrou-se trabalhos com conteúdo sobre a temática, no entanto, nenhum que tratasse da aproximação ora proposta. Assim, foi possível a construção do constructo teórico, que fundamentou o alinhamento objeto deste estudo.

Para o tratamento de dados fez-se uso da análise do conteúdo, que abarca diversas propostas de métodos complementares Bardin (2011), entre eles a categorização, escolha para este estudo, por sua característica de "[...] 
fornecer, por condensação, uma representação simplificada dos dados brutos" (Bardin 2011, p. 148). Assim, as categorias analíticas desta reflexão se manifestam a partir dos elementos

constituintes da aprendizagem colaborativa/coaprendizagem, os quais, supõe-se servem de estrutura para a consolidação da educação continuada. Na sequência, na análise e discussão dos dados, apresenta-se a proposição ora exposta, a qual materializa o objetivo deste estudo.

\section{Análise e Discussões}

Considerado o objetivo deste estudo e a teorização apresentada, reflete-se acerca do alinhamento entre a Aprendizagem Colaborativa/Coaprendizagem e Educação Continuada. Acredita-se primeiramente, que o ponto focal é o sujeito inserido em um processo coletivo, que promove a continuidade da aprendizagem, por meio do compartilhamento de conhecimento.

Nessa direção, verifica-se que o aprender a conhecer, caracterizado pela concepção de que o processo da aprendizagem nunca acaba e pode enriquecer-se com qualquer experiência (Delors, 2004). Essa última, por sua vez, pode ser materializada a partir da interação entre sujeitos que compartilham conhecimento entre si (Leite et al, 2005). Pertencer a um grupo pode inclusive motivar e proporcionar o prazer de compreender, conhecer e descobrir, conforme aponta Delors (2004).

Outro elemento de proximidade entre a educação continuada e a aprendizagem colabarativa/ coaprendizagem é o fato de que a primeira traz como caracterização a questão do conhecimento múltiplo, que evolui infinitamente e transmite as pessoas impulsos para continuarem a aprender durante toda a vida, que é compartilhada em sociedade. Acredita-se ainda, que essa interação social provoca no sujeito a compreensão de determinado fenômeno, a partir de diversas reinterpretações, reconstruções e redistribuições de informações (Okada, 2014).

O aprender a fazer está associado à questão profissional, em como ensinar o sujeito a colocar em prática os seus conhecimentos e, também, como adaptá-los ao trabalho futuro. É interessante pensar no aprender a fazer como a parte empírica do aprender a conhecer e, nessa direção, o conhecimento socialmente construído pela aprendizagem colaborabiva/coaprendizagem (Lupion Torres, Alcantara, \& Freitas Irala, 2004) alcança posicionamento palpável.

É interessante lembrar que Delors (2004), no contexto do segundo pilar, aponta que o progresso técnico modifica, inevitavelmente, as qualificações exigidas pelos novos processos de produção e, sendo assim, as tarefas físicas são substituídas pelas mais intelectuais, mentais. Ou seja, os processos evoluem e exigem do sujeito a compreensão do novo para pô-lo em prática, fato que a aprendizagem colaborativa/coaprendizagem contempla quando na posição de ser um processo por meio do qual a interação e a troca entre os sujeitos, tem por objetivo melhorar a competência dos sujeitos, por intermédio dos trabalhos cooperativos que acontecem em grupos (Leite et al., 2005).

O terceiro pilar aprender a viver juntos, aprender a viver com os outros, segundo Delors (2004) instiga o papel do conhecimento em fazer com que o sujeito tome consciência das semelhanças e da interdependência 
entre as pessoas. $O$ autor aponta que na busca pelo conhecer o outro, necessariamente, o sujeito compreende a si mesmo e que a educação formal deve reservar em seus programas momentos para projetos de cooperação, inclusive levando para a prática diária a aprendizagem de métodos de resolução de conflitos.

Observa-se que a aprendizagem colaborativa/coaprendizagem promove a aproximação entre os membros de uma equipe (Cord, 2000), os quais constroem uma comunidade do conhecimento, em outras palavras, o conhecimento é socialmente construído (Lupion Torres, Alcantara, \& Freitas Irala, 2004), por meio de um processo dinâmico entre sujeitos que cooperam entre si. A interação, na aprendizagem colaborativa/coaprendizagem tem como base uma visão ético-crítica (Okada, 2014, p. 16), fato que sustenta a concepção do terceiro pilar em relação ao conhecer o outro e conhecer a si mesmo e, ainda, a questão da tomada de consciência sobre a diversidade humana.

Aprender a ser, o quarto pilar, considera que a educação dever contribuir para o desenvolvimento total do sujeito (Delors, 2004). Nessa direção, o autor aponta o papel da aprendizagem em proporcionar ao indivíduo a construção de pensamentos autônomos e críticos e formular seus próprios juízos de valores, fato que sustenta o poder de decidir, por si só, como agir. Essa última ação envolve liberdade de pensamento, discernimento, sentimentos e imaginação e a construção de um processo dialético que se inicia, conforme já expresso, com o conhecimento de si mesmo para depois se abri em relação ao outro (Delors, 2004).

Sob essa perspectiva, também transita a aprendizagem colaborativa/coaprendizagem visto que, apesar da ideia do compartilhamento, respeita e destaca as contribuições individuais (Panitz, 1999). Ainda, segundo o autor, trata-se justamente de um conjunto de processos que ajuda o sujeito (que conhece a si mesmo/tem seus próprios conhecimentos) a interagir, ou seja, a se abrir em relação ao outros e compartilhar o conhecimento. A Figura 4 apresenta uma síntese do ora discutido.

\section{Figura 4}

Síntese do alinhamento entre educação continuada e aprendizagem colaborativa/coaprendizagem

\begin{tabular}{lr}
\multicolumn{1}{c}{ Educação Continuada - Pilares } & Aprendizagem Colaborativa/Coaprendizagem \\
\hline Aprender a Conhecer & Reinterpretações, reconstruções e redistribuições de informações. \\
Aprender a Fazer & Interação e troca com objetivo de melhorar a competência dos sujeitos, por \\
& intermédio de trabalhos cooperativos. \\
Aprender a viver juntos, aprender a & Compartilhamento com respeito e destaque para as contribuições individuais. \\
\multicolumn{1}{c}{ viver com os outros } & \\
Aprender a ser & Aproximação entre os membros de uma equipe - o eu e o outro.
\end{tabular}

Nota: Elaborado pelos autores (2019).

A síntese exposta na Figura 4 confirma a aproximação entre as teorias e, ao se pensar em estratégias para o ensino, que a aprendizagem colaborativa/coaprendizagem se "encaixa" como abordagem estruturante da educação continuada. Em outras palavras, o ora refletido possibilita a compreensão de que o ser humano vive em sociedade, a qual está inserida em um mundo dinâmico, no qual as mudanças são uma constante e, se assim for, a educação/ 
aprendizagem não pode ser um fenômeno "engessado", pelo contrário deve-se compreendê-lo como um processo evolutivo e, desse modo, a aprendizagem deve ocorrer ao longo da vida do sujeito.

Considerado o processo de o aprendizado ocorrer durante toda a vida do sujeito e que esse sujeito vive em uma sociedade, esta reflexão verifica, em termos teóricos, que a aprendizagem colaborativa/coaprendizagem, por seu propósito, que é o compartilhamento do conhecimento e a cooperação entre os indivíduos, fundamenta as perspectivas daquilo que se espera em termos de continuidade da aprendizagem - educação - conhecimento. Por conseguinte, o questionamento inicial deste estudo sobre como se materializa o alinhamento entre a educação continuada e a aprendizagem colaborativa/coaprendizagem, encontra bases sólidas em termos teóricos, que inclusive fomentam a concepção de que a segunda serve como estratégia para o desenvolvimento da primeira.

\section{Considerações Finais}

Ao final desta reflexão, que tratou de ponderar sobre a existência de aproximação entre a aprendizagem colaborativa/coaprendizagem e a educação continuada, considera-se que os fenômenos são complementares. A linha de teórica analisada possibilitou a compreensão de que a aprendizagem não é algo que pode ser "engessado" ou, em outras palavras, que se adquire em um determinado momento da vida e, que a partir disso, o sujeito está munido de todo conhecimento necessário para desenvolver-se seja em termos sociais ou profissionais.

Nesse sentido, considerou-se que a abordagem da aprendizagem, cuja proposta envolve o compartilhamento de informações "encaixaria-se" como elemento estruturante de desenvolvimento da educação continuada. A lógica é a de que se o sujeito vive em uma sociedade, seja em termos sociais ou

profissionais, ele convive com outras pessoas e, assim, compartilhar conhecimento seria uma forma de cooperação entre todos, visando o aprimoramento tanto em termo individuais como coletivos.

Discutiu-se, também, durante o dissertado, sobre os pilares da educação, bases da educação continuada, o aprender a conhecer, a fazer, a viver juntos e a ser. Considerados esses pilares e a abordagem da aprendizagem colaborativa/coaprendizagem, observou-se que os aspectos teóricos estruturantes de uma e outra teoria se correlacionam e, sendo assim, uma serve de alicerce estratégico para a outra, todavia, para estudos futuros sobre a temática sugere-se a aplicação empírica do ora discutido.

Em termos de limitações aponta-se justamente a questão de ser um ensaio teórico, que necessita ser tratado, ainda, empiricamente. Todavia, julga-se válida a discussão teórica precedente as contestações

práticas, visto que em se tratando de métodos é permitido esse tipo de sustentação. E, nessa direção está a contribuição deste estudo, ou seja, apresentar um constructo teórico para ancoramento de uma futura verificação in loco. 


\section{Referências}

Arouca, L. S. (1996). O discurso sobre educação permanente (1960-1983). Pro-posições, 7(2), 65-78. Recuperado em 30 novembro, 2019, de https://periodicos.sbu.unicamp.br/ojs/index.php/proposic/article/view/8644229

Ausubel, D. (1983). Teoría del aprendizaje significativo. Fascículos de CEIF, 1(1-10).

Bardin, L. (2011). Análise de conteúdo. São Paulo, SP: Edições 70.

Cord, B. (2000). Internet et pédagogie - état des lieux. Recuperado em 29 novembro, 2019 de http://wwwadm. admp6.jussieu.fr/fp/uaginternetetp/definition travail colboratif.htm

Creswell, J. W. (2009). Research design: qualitative, quantitative and mixed approaches. London: Sage Publications. Delors, J. (2004). Educação: um tesouro a descobrir. Brasília, DF: UNESCO.

Dillenbourg P. (1999) What do yuo mean by collaborative leraning? In: P. Dillenbourg (Ed) Collaborative-learning: Cognitive and Computational Approaches. (pp. 1-19). Oxford: Elsevier Recuperado em 30 novembro, 2019 de https://telearn.archives-ouvertes.fr/hal-00190240/document

Eboli, M. (2001). Um novo olhar sobre a educação corporativa - desenvolvimento de talentos no Século XXI. In: Dutra, J. S. (Org.). Gestão por competências: um modelo avançado para o gerenciamento de pessoas, (2a. ed.). São Paulo: Editora Gente.

Ferreira, A. B. H. (1999). Novo dicionário da língua portuguesa. Rio de Janeiro: Nova Fronteira.

Gerhardt, T. E., \& Silveira, D. T. (2009). Métodos de Pesquisa. Porto Alegre, RS: Editora da UFRGS.

Küller, J. A., \& Rodrigo, N. F. (2013). Metodologia de desenvolvimento de competências. Rio de Janeiro: SENAC Nacional.

Laal, M., \& Laal, M. (2012). Collaborative learning: what is it? Procedia-Social and Behavioral Sciences, 31, 491-495. Le Boterf, G. (1999). Competénce et navigation professionnelle. Paris: Éditions d'Órganisation.

Le Boterf, G. (2003). Desenvolvendo a competência dos profissionais. Trad. Patrícia Chittoni Ramos Reuillard. Porto Alegre: Artmed.

Leite, C. L. K., Passos, M. O. A., Torres, P. L., \& Alcantara, R. A. (2005). A Aprendizagem Colaborativa na Educação a Distância on-line. In: Congresso Internacional de Educação a Distância. Recuperado em 20 novembro, 2019 de https://www.researchgate.net/profile/Cristiane Luiza/publication/267254318 A APRENDIZAGEM COLABORATIVA NA EDUCACAO A DISTANCIA ON-LINE/links/5540beee0cf23222272f49c7/AAPRENDIZAGEM-COLABORATIVA-NA-EDUCACAO-A-DISTANCIA-ON-LINE.pdf

Lupion Torres, P., Alcantara, P. R., \& Freitas Irala, E. A. (2004). Grupos de consenso: uma proposta de aprendizagem colaborativa para o processo de ensino-aprendizagem. Revista diálogo educacional, 4(13). Recuperado em 20 novembro, 2019, de http:// wwwadm.admp6.jussieu.fr/fp/uaginternetetp/ definition travail colboratif. $\underline{\mathrm{htm}}$

Okada, A. (2014). Competências chave para coaprendizagem na era digital: fundamentos, métodos e aplicações. Santo Tirso - Portugal: Whitebooks. 
Oxford, R. L. (1997). Cooperative Learning, Collaborative Learning, and Interaction: three communicative strands in the language classroom. The Modern Language Journal, 81(4), $443-456$.

Panitz, T. (1999). Collaborative versus cooperative learning- a comparison of the two concepts which will help us understand the underlying nature of interactive learning. Recuperado em 20 janeiro, 2019 de https://files. eric.ed.gov/fulltext/ED448443.pdf

Perrenoud, P. (1999). Profissionalização do Professor e Desenvolvimento de Ciclos de Aprendizagem (Passagens). Faculdade de Psicologia e das Ciências da Educação Universidade de Genebra, Cadernos de Pesquisa, 108, novembro.

Piaget, J. (1964). Development and learning. Journal of Research in Science Teaching, New York, 2(3), 176-186.

Prosdócimo, Z. P. A., \& Ohira, M. L. B. (2000, setembro). Quem é o bibliotecário em exercício no Estado de Santa Catarina: necessidade de educação continuada. Anais do Congresso Brasileiro de Biblioteconomia e Documentação. Porto Alegre.

Salvador, C. C. (1994). Aprendizagem escolar e construção do conhecimento. Porto Alegre: Artes Médicas.

Santos, C. M. (1999). Educação continuada. (Dissertação). Faculdade de Educação - Universidade Bandeirante de São Paulo. São Paulo. Brasil.

Saunders, M., Lewis, P., \& Thornhill, A. (2009). Research methods for business students (5th ed.). New York: Prentice Hall Inc. https://doi.org/10.1007/s13398-014-0173-7.2

TRIVIÑOS, A. N. S. Introdução à Pesquisa em Ciências Sociais: a pesquisa qualitativa em Educação. São Paulo: Atlas, 2012.

Vygotsky, L. S. (1989). Concrete human psychology. Soviet psychology, 27(2), 53-77.

Vergara, S. C. (2010). Projetos e relatórios de pesquisa em administração. São Paulo: Atlas S.A.

Whetten, D. (1989). What constitutes a theoretical contribution? Academy of Management Review, 14(4). 